\title{
Nutrition interventions to reduce diarrhoea morbidity and mortality
}

\author{
Ann Ashworth* \\ Human Nutrition Unit, London School of Hygiene and Tropical Medicine, Keppel Street, London WCIE 7HT, UK
}

Despite improved case management, diarrhoeal diseases still account for an estimated $23 \%$ of all deaths among children aged $0-4$ years (World Health Organization (WHO), 1995a). Diarrhoeal diseases are largely confined to developing countries and, given their very limited health budgets (typically < US \$5/person per year), it is essential to identify cost-effective strategies for disease prevention. With this in mind, in 1982 the Diarrhoeal Diseases Control Programme of WHO initiated a systematic and comprehensive review of a wide range of potential non-clinical interventions for the reduction of diarrhoeal morbidity and/ or mortality among infants and young children (Feachem $e t$ al. 1983). The potential strategies were primarily of two kinds: (a) strategies that increase host resistance to infection and/or death, (b) strategies that reduce transmission of diarrhoeal pathogens.

After the reviews were completed, the potential interventions were assigned to one of three categories (Feachem, 1986). In group 1 were strategies for which there was already good evidence that they would be effective, feasible and affordable, and the expectation was that these would be implemented within national primary health care programmes. Assigned to group 2 were strategies of uncertain effectiveness, feasibility or cost, requiring more research. In group 3 were strategies that were ineffective or excessively costly and could be disregarded. Of the eighteen potential interventions examined, seven were primarily nutritional interventions and these were assigned as follows:

group 1 promotion of breast-feeding, improving weaning practices;

group 2 prevention of low birth weight (LBW), improving food hygiene, vitamin A supplementation;

group 3 enhancing lactation, supplementary feeding programmes.

In the present paper, I shall consider some of the developments, experiences and new knowledge that have emerged since the reviews were completed. I shall restrict myself to the nutrition interventions assigned to group 1 (for implementation) and group 2 (requiring further research), but omitting vitamin A supplementation which is considered separately in the present symposium (Ross, 1998).

\section{Promotion of breast-feeding}

Exclusive breast-feeding protects against diarrhoea in the early months of life by enhancing the infant's resistance to infection and minimizing exposure to water-borne and food-borne pathogens. Exclusive breast-feeding can completely mitigate the risk posed by crowded, highly contaminated environments (VanDerslice et al. 1994). Since even small amounts of contaminated water can double the risk of diarrhoeal disease (Brown et al. 1989), exclusive breast-feeding is emphasized when promoting breast-feeding for diarrhoeal disease control and child survival (Shahidullah, 1994). Partial breast-feeding also protects, but to a much lesser extent than exclusive breastfeeding (Feachem \& Koblinsky, 1984).

Previously, data were available from twenty-one studies from eight countries (almost all industrialized) documenting the impact of local promotion campaigns on breastfeeding prevalence (Feachem \& Koblinsky, 1984). Based on these findings, theoretical calculations indicated that breast-feeding promotion would be expected to reduce diarrhoea morbidity rates by $8-20 \%$ among infants aged $0-5$ months, and diarrhoea mortality by $24-27 \%$. Costeffectiveness was not well-documented and it was recommended that operational research be undertaken in developing countries to identify the most cost-effective designs for breast-feeding promotion, and where possible, to measure the impact on diarrhoea rates. Some additional information is now available on impact and cost-effectiveness, and is reported here, with a focus on developing countries.

\section{Impact of breast-feeding promotion on breast-feeding prevalence}

Accurate estimates of breast-feeding trends are difficult to obtain. The Demographic Health Surveys and World Fertility Surveys indicate no consistent pattern, with durations declining in some countries and increasing in others (Trussell et al. 1992). Changes in population characteristics in developing countries (urbanization, edu-

\footnotetext{
Abbreviations: LBW, low bitth weight; UNICEF, United Nations Children's Fund; WHO, World Health Organization.

* Corresponding author: Dr A. Ashworth, fax +44(0)171 383 5859, email a.hill@1shtm.ac.uk
} 
cation etc), contribute to declining trends, but within population subgroups, trends are often positive (GrummerStrawn, 1996). This could indicate that breast-feeding promotion is having an impact, although other factors should also be considered, such as increased birth intervals and economic downturns.

Prominent among the promotion strategies espoused by WHO and United Nations Children's Fund (UNICEF) are (1) the Baby Friendly Hospital Initiative which sets minimum standards of practice for maternity care facilities (WHO/UNICEF, 1989), (2) establishment of breast-feeding training programmes and courses to redress the global shortage of experienced breast-feeding counsellors, and (3) the International Code of Marketing of Breast-milk Substitutes aimed at supporting and protecting breastfeeding by, for example, proscribing the advertising of infant formula to consumers (WHO, 1981). To these can be added other legislative measures such as maternity leave and breast-feeding breaks, social support networks, and mass media programmes. Whether these strategies are having an impact has been questioned (Wilmoth \& Elder, 1995). Although most of the seventeen studies from developing countries reported positive outcomes, Wilmoth \& Elder (1995) point to the difficulty in drawing conclusions because of flawed research methods, inadequate descriptions of the programmes and outcomes, and failure to consider potential socio-demographic confounders in the analysis. Experience in implementing Baby Friendly Hospital Initiatives and related activities in twenty-six countries of Central and Eastern Europe, and in the Baltic region and Commonwealth of Independent States, indicates that progress can be slow (UNICEF, 1996). After 3 years, achievement scores were modest. The programme area with the lowest average score was implementation of the Marketing Code, followed by monitoring and evaluation. The best achievements were in capacity building and training activities. Programme performance was poorest in countries with the highest under-5 years mortality rates.

Impact of improving maternity ward procedures. PérezEscamilla et al. (1994), in their overview of studies published from 1951 to 1991 , restricted their analysis to randomized trials or quasi-experimental designs with adequate documentation, and used meta-analysis where possible. Of sixty-five studies located, eighteen met the inclusion criteria. They concluded that several of the WHO/ UNICEF policies, notably rooming-in, breast-feeding guidance, and no free samples, can have a positive impact on breast-feeding success. Few of these studies, however, were from developing countries.

Lutter et al. (1994) reviewed the effect of breast-feeding promotion activities in seven hospitals in Latin America. The hospital with the most comprehensive programme was the Guillerme Alvaro Hospital in Santos, Brazil, and there the median duration of exclusive breast-feeding was $75 \mathrm{~d}$. In general, the most common promotional activities in the seven hospitals were ones that resulted in fewer personnel and hence saved on costs, such as rooming-in and the elimination of prelacteal feeds and formula. These activities, however, had relatively little impact on the duration of exclusive breast-feeding, with medians ranging from $6 \mathrm{~d}$ in Mexico to $23 \mathrm{~d}$ in Brazil. Less common were activities that required an on-going commitment of resources and motivated personnel, such as lactation management, education and counselling, yet it is these activities that seem to have the greatest impact on exclusive breast-feeding duration.

Impact of training. Particular emphasis regarding breastfeeding promotion has been given to in-service training of health professionals, for example through the $40 \mathrm{~h}$ WHO/ UNICEF counseliing course (WHO, 1993a). Westphal et al. (1995) have evaluated the $18 \mathrm{~d}$ breast-feeding course at the Santos Lactation Centre which is attached to a designated Baby Friendly Hospital in Santos, Sao Paulo, Brazil. The course is modelled on that at the Wellstart Center in San Diego, CA, USA and eight maternity hospitals were studied: four were randomly allocated to the intervention group and each sent three health professionals to attend the course. The remaining four maternity hospitals served as controls. Compliance with WHO/ UNICEF (1989) 'Ten steps for successful breastfeeding' was determined before and 6 months after the training course. Despite the trainees' intentions to implement changes in their home institution, difficulties were encountered, especially when trying to change established (but undesirable) routines such as delayed first contact, giving prelacteal feeds, separating mother and baby, and using pacifiers. More easily implemented were new activities such as creation of outpatient clinics for promotion of breast-feeding. These difficulties may have arisen because the trained professionals had little decisionmaking power and there was no institutional policy giving priority to breast-feeding promotion and allocating to it human and physical resources. In the intervened facilities, increases in the median duration of breast-feeding were $5 \mathrm{~d}$ of exclusive breast-feeding, $13 \mathrm{~d}$ of predominant, and $30 \mathrm{~d}$ of any breast-feeding in the first 6 months of life. No increases were observed in the control facilities (WHO, 1994). Constraints in implementing the 'ten steps' have also been reported from a teaching hospital in Arizona (Wright et al. 1996), primarily because it was not seen as a priority by administrative staff.

Prasad \& Costello (1995), evaluating the impact of 'baby-friendly' training for health staff in an Indian hospital, found greatly improved breast-feeding practices initially, but 6 months later, few staff contacts were baby friendly, and feeding practices had reverted back to the traditional practices. They conclude that training must be reinforced at regular intervals to take account of staff turnover and loss of interest, and that performance should be checked through routine monitoring using simple indicators.

The need for continuity of effort is also illustrated by experience in Brazil. In 1981, a high-profile, imaginative national breast-feeding programme was established which included an intensive media campaign, training for health professionals and traditional healers, establishment of mothers' self-help support groups, new labour laws, and control of the marketing of breast-milk substitutes. In Sao Paulo, the programme was estimated to have increased the percentage of babies predominantly or exclusively breastfed at 3-4 months from 4 to $39 \%$ (Rea \& Berquo, 1990). 
Nationwide coordination ended in 1985 , and although some lasting benefits remain, such as rooming-in policies and legislative changes, much of the success was soon lost. During 1993, health professionals in 192 facilities in northeast Brazil were assessed in relation to diarrhoea treatment and prevention. Although almost all had a good level of knowledge about colostrum and exclusive breast-feeding, only $2.3 \%$ stated that they considered breast-feeding information to be important when advising care-givers about diarrhoea prevention (Ribeiro \& Drasbek, 1995).

Impact of breast-feeding counsellors. In many developing countries, low-income mothers often deliver at home, so 'baby-friendly' hospital routines will have no impact on their breast-feeding practices. Also, strategies that focus on mothers only at delivery are likely to have limited impact, especially as they often remain only 12-24 h. Prenatal and postnatal interventions, giving mothers an opportunity to discuss their concerns in an unhurried manner, may be more effective than trying to persuade mothers at delivery. Including fathers and other influential family members in these discussions may curtail the potential negative influence of these family members. In developing countries, most mothers initiate breast-feeding, and the main cause for concern is the inappropriate introduction of additional fluids and the rejection of colostrum. Local women are being trained in some countries to serve as breast-feeding counsellors.

In Dhaka, Bangladesh, where most deliveries are at home, a randomized controlled trial of peer counsellors is currently in progress in forty urban communities. Two home visits are made during the third trimester of pregnancy and then three more within the first $10 \mathrm{~d}$ of delivery; thereafter, monthly visits are made. The objective is to promote exclusive breast-feeding for 5 months in communities that traditionally give prelacteal feeds, water and complementary feeds from birth. Preliminary results indicate $85 \%$ of intervened mothers are exclusively breastfeeding at $4 \mathrm{~d}$ postpartum, compared with $30 \%$ of control mothers (Haider et al. 1998). Differences of similar magnitude continue to be seen during follow-up. Rates might be even higher if health professionals stopped giving conflicting and incorrect advice, undermining the mother's confidence in her peer counsellor.

In Chile, success has also been achieved among lowincome women in Santiago. Peer counsellors provided prenatal, perinatal and postnatal support and, at 4 months, $90 \%$ of intervened mothers were breast-feeding exclusively compared with $8 \%$ of control mothers. At 6 months, the corresponding percentages were $42 \mathrm{v} .0 \%$ (Alvarado et al. 1996).

In Pakistan, sick infants at the Children's Hospital, Islamabad, can be referred to the Lactation Management Clinic if they are not optimally breast-fed. When first referred, 'insufficient milk' was reported by $45 \%$ of mothers as the main feeding problem but, on observation, counsellors found that in at least two-thirds of cases the underlying problem was poor attachment of the infant to the breast. Correct placing was associated with a return to exclusive breast-feeding in the majority of these mothers (WHO, 1996). When first referred, fewer than $1 \%$ were exclusively breast-feeding, but 3 months later, $69 \%$ of those counselled were exclusively breast-feeding compared with $19 \%$ among those who were referred but chose not to attend (WHO, 1994).

Role of mass media communications. There has been little systematic use of large-scale mass media campaigns in breast-feeding promotion (McDivitt et al. 1993). In Jordan, knowledge about early initiation and the benefits of colostrum increased dramatically with intensive television and radio campaigns, but the actual impact on initiation was small, probably because maternity ward procedures were not reinforcing (McDivitt et al. 1993). Indeed, the impact was greatest among home deliveries. Green (1989) concludes that two major lessons emerge from past experience of mass-media campaigns: (1) general messages proclaiming the benefits of breast-feeding are not effective, since they do not address the obstacles mothers face in implementing optimal breast-feeding practice, (2) breastfeeding promotion needs to be placed within a larger institutional framework, involving policy makers, administrators and employers, to ensure sustainability of promotional programmes. Mass media can play a useful role in helping to change group norms, but only if part of a longrange promotion strategy. With the advent of the International Code of Marketing of Breast-milk Substitutes (WHO, 1981), many national breast-feeding promotion programmes and mass-media campaigns had their funding cut back or withdrawn, in part because policy makers in governments and donor agencies felt removal of commercial advertising would improve breast-feeding rates (Green, 1989).

\section{Impact of breast-feeding promotion on diarrhoea rates}

Feachem \& Koblinsky (1984) previously reported that in Costa Rica, improved hospital practices were associated with a $36 \%$ reduction in diarrhoea in infants aged $0-5$ months. Two subsequent morbidity studies have been located, both of which relate to postpartum promotion through breast-feeding counselling. In Guarujá, Brazil, infants recruited in the perinatal period, whose mothers subsequently attended lactation centres, were more likely to be exclusively breast-fed at 4 months than non-attenders (43 v. $18 \%$ ) and also at 6 months $(15$ v. $6 \%$ ). Differences in diarrhoea prevalence approached statistical significance at 4 months $(P=0.09)$ and were significant at 6 months (adjusted odds ratio $0.52,95 \% \mathrm{CI} 0.30-0.91$ ). Weight-forage was also significantly better among attenders (Barros et al. 1995).

In Bangladesh, partially-breast-fed infants admitted to hospital with diarrhoea were randomized to counselling during their hospital stay and at home 1 week after discharge. Control mothers also received follow-up at home but were not individually counselled. When assessed 2 weeks after discharge, $75 \%$ of infants in the intervention group were exclusively breast-fed compared with $8 \%$ of controls, and the intervened group were less likely to have had another episode of diarrhoea (odds ratio $2.92,95 \% \mathrm{CI}$ 0.86-10.92; Haider et al. 1996). In Pakistan, increased exclusive breast-feeding associated with simple health messages in the prenatal and postnatal periods has been 
reported to be associated with decreased diarrhoea in the first 6 months (Prasad \& Costello, 1995).

\section{Improving weaning practices}

Diarrhoeal morbidity and mortality tend to peak during the weaning period. Weaning food contamination is one major cause of diarrhoea and is addressed here under food hygiene. Faulty weaning practices are also of concern as malnutrition predisposes towards increased severity and duration of diarrhoea and to increased risk of diarrhoea mortality (Feachem, 1983). Faulty practices include infrequent meals, small servings, foods of poor quality (low energy and nutrient concentration and/or specific nutrient deficits), inadequate encouragement and supervision, and dietary monotony.

No information was available at the time of the reviews as to whether the promotion of improved weaning practices (defined as improvements in the 'when, what and how' of complementary feeding) led to reduced diarrhoea rates, although several studies showed that weaning education improved nutritional status (Ashworth \& Feachem, 1985a). It was recommended that research be carried out in which minimal and specific changes in weaning practice are made and the impact on diarrhoeal disease monitored. No morbidity studies have been located, but further studies have been conducted to determine whether focused weaning education results in improved anthropometric status.

In rural Bangladesh, a community-based education intervention used volunteers to promote timely introduction of complementary foods at 5-6 months, snacks, and enrichment of weaning foods. Active encouragement and supervision at meal-times were also advocated. Of the promoted behaviours, the most frequently implemented were those requiring little time and money (Brown et al. 1992). During a 5-month period, intervened infants gained significantly more weight than control infants $(0.46 \mathrm{SD}$ weight-for-age, $P<0.001)$. No significant improvement in anthropometric status was observed, however, in three other intervention studies, despite the fact that significant behavioural changes were achieved, i.e. frequency and quality in the Philippines, quantity and quality in Peru, and quality in Nigeria (WHO, 1993b). In Peru, the specific behaviours were promoted in ten peri-urban communities through local community organizations and health service staff. The proportion of the population offering 'thick foods' of high energy density, and feeding frequently, increased from 12 to $45 \%(P=0.001)$. The mean energy density of complementary foods offered to infants aged $6-$ 12 months, increased from 2.6 to $3.4 \mathrm{~kJ} / \mathrm{g} \quad(P<0.005$; Kanashiro et al. 1994). These intervention studies were not 'top down' but followed 'best practice' in which culturally sustainable behaviours were identified through previous ethnographic research and an interdisciplinary approach (Scrimshaw \& Hurtado, 1987; Bentley et al. 1991). The active participation of mothers and other members of the community was sought, and the feasibility of the proposed interventions was pre-tested through household trials (Kanashiro et al. 1991; Guptill et al. 1993). Their lack of impact on growth could be because targeted behaviours were only intermittently changed, or were changed initially but not sustained, or that the quantities consumed were still small. It is also possible that the targeted behaviours were marginal among an array of more important determinants of inadequate growth, and/or that specific micronutrient deficits persisted, for example of $\mathrm{Zn}, \mathrm{Fe}$ and vitamin $\mathrm{A}$.

Counselling about weaning is an integral component of the WHO/UNICEF Integrated Management of Childhood Illness Programme (WHO, 1995a). At every clinic contact for children aged $<2$ years, a feeding assessment is carried out, whether the child is undernourished or not, and then compared with age-specific recommendations. The counselling focuses on remediable feeding problems and negotiating specific changes with the care-giver, rather than dispensing general nutritional advice. Counselling about breast-feeding is also part of this process, and health workers are trained to help mothers overcome difficulties.

\section{Prevention of low birth weight}

The main research priority identified during the systematic review process was to determine the relative risk of diarrhoeal illness and death by birth weight in different socio-economic settings (Ashworth \& Feachem, 1985b). The feasibility of achieving a substantial reduction in the prevalence of LBW in the short term was questioned, and the costs of such interventions were unknown. New knowledge is helping to clarify these uncertainties.

\section{Relative risk of diarrhoeal illness and death in infants of low birth weight}

Infants of LBW may differ in several important respects from infants of appropriate birth weight. For example, LBW infants are more likely to be from poor families with less favourable living conditions. Studies that aim to quantify the risk of diarrhoea in LBW infants must, therefore, control for these other confounding factors. The results from two such studies are now available: in Papua New Guinea, LBW infants aged 0-17 months had 70\% more days with diarrhoea than infants of appropriate birth weight $(P<0.001$; Bukenya et al. 1991), and in Brazil the difference in prevalence was $33 \%(P=0.003$; Lira et al. 1996). It is now also clear that LBW is an important determinant of hospitalization for diarrhoea (Victora et al. 1992) and of diarrhoeal death (Barros et al. 1987; Victora et al. 1988).

\section{Interventions to prevent low birth weight}

Gulmezoglu et al. (1997) have reviewed the impact of prenatal interventions to prevent or reduce impaired fetal growth. The interventions included both nutritional and non-nutritional interventions. They used systematic reviews of randomized controlled trials from the Cochrane Pregnancy and Childbirth Database, and concluded that those most likely to be beneficial are anti-smoking interventions, malaria chemoprophylaxis for primigravidae, and protein-energy supplementation in undernourished 
women. In a randomized trial in twenty-eight communities in The Gambia, the incidence of LBW was $33 \%$ less in the intervened communities (Ceesay et al. 1997). Although prenatal nutrition interventions can reduce LBW, the operational question will be their cost-effectiveness.

\section{Postnatal interventions to reduce diarrhoea in low birth weight infants}

Not considered in the series of systematic reviews were postnatal interventions that would specifically target LBW infants. Since LBW infants are now known to be at increased risk of diarrhoeal illness, it is appropriate to examine interventions that might increase the resistance of LBW infants to diarrhoea. In north-east Brazil, supplementation of LBW infants with $5 \mathrm{mg} \mathrm{Zn}$ daily, except Sundays, for 8 weeks from birth, was associated with a $28 \%$ reduction in diarrhoea during the first 6 months of life, after adjusting for confounders $(P=0.043$; Lira et al. 1998). $\mathrm{Zn}$ supplementation appeared to offset the excess diarrhoeal morbidity that these LBW infants experience in this community.

\section{Improving food hygiene}

Certain behaviours are more difficult to study than others, and hygiene is one example. A further difficulty in planning interventions for modifying unsafe food hygiene practices is deciding which behaviours should be prioritized for change, as educational interventions can transmit only a limited number of messages. Recent research has concentrated on the identification of key foods and key practices for pathogen transmission. The impact on diarrhoea morbidity and mortality of promoting improved food hygiene remains unknown.

\section{Identification of key foods and key practices in diarrhoeal pathogen transmission}

In preparing, handling and storing foods, there are numerous points at which contamination occurs. Foods are often contaminated, then decontaminated by boiling or cooking, and then recontaminated. The classical approach for determining critical hazard points is expensive and of limited use in developing countries, as it fails to take into account cultural and resource constraints which may limit behavioural change. In Guatemala, preliminary formative research established the socio-cultural context of hygiene behaviours and then selected handwashing and reheating of tortillas and beans as the target behaviours, based on their expected impact on diarrhoea and feasibility for change. The study then developed, through experimental cooking trials, instructional messages to reduce pathogen contamination. For example, for reheating tortillas to a temperature at which vegetative forms of enteropathogens are killed $\left(>70^{\circ}\right)$, the instruction was to dampen the tortilla slightly and then 'reheat on a hot slab until no water is left and the tortilla is beginning to turn brown and it burns your hand' (WHO, 1995b). The acceptability of the proposed behavioural changes was tested through household trials.
Handwashing was reported to be well accepted, as was reheating of beans (fourteen of fifteen trials). Reheating tortillas was less acceptable (eleven of fifteen trials) due to time and fuel constraints.

In a slum area of Fortaleza, north-east Brazil, four food hygiene behaviours were identified as a priority for change through a combination of ethnographic, survey and observational methods, and by integrating viewpoints and suggestions of care-givers into the decision-making process (Monte et al. 1997). The feasibility of adopting the advocated behaviours was tested in a 1-month household trial in which mothers who did not practise the advocated behaviour were encouraged to do so. Boiling water when reconstituting milk feeds, and not storing feeds, were each sustained by twelve of fifteen mothers. Handwashing before handling food and preparing meals was achieved by eleven of fifteen mothers, and feeding by spoon instead of a bottle was the least easy practice to sustain (nine of fifteen mothers).

Ethnographic research features prominently in current studies of food hygiene. This is to be welcomed, as it is only by a better understanding of the socio-cultural context that feasible interventions can be defined. I was certainly surprised to learn that in a rural area in northern Thailand, the ripe banana, so often extolled for its convenience and purity, has a high coliform count when fed as a weaning food, as it is mashed in the palm of the hand (Imong et al. 1995).

\section{Fermented foods and reduced diarrhoeal pathogen transmission}

Fermented cereal porridges, such as ogi, are traditionally given as weaning foods in Africa (Ashworth \& Draper, 1992). During the fermentation process, lactic and other acids are released, lowering the $\mathrm{pH}$, and possibly generating anti-microbial substances (Mensah et al. 1988, 1990). Pathogenic Escherichia coli are usually the commonest diarrhoeal agent in developing countries and transmission has been specifically linked with weaning foods (Motarjemi et al. 1993). Odugbemi et al. (1991) demonstrated that when enteropathogenic $E$. coli were inoculated into

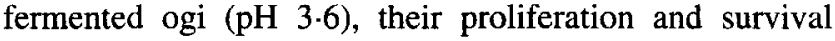
were inhibited. Salmonella pathogens were also inhibited, but to lesser degree than $E$. coli. In Tanzania, Lorri \& Svanberg (1994) monitored diarrhoeal rates over 9 months in 201 children under 5 years. Those in a village consuming fermented gruels had a $40 \%$ lower frequency of diarrhoea than children in a nearby village consuming non-fermented gruels $(2.1$ v. 3.5 episodes; $P<0.001)$.

\section{Cost-effectiveness of nutrition interventions}

There remains a lack of data from programmes under operational conditions. Horton et al. (1996) have examined the costs and impacts of breast-feeding promotion in maternity wards in Brazil, Honduras and Mexico. They conclude that where programmes shift maternity-ward practices from substantial formula use to almost no formula use (as in Mexico), cost-effectiveness is likely to be high, with costs of approximately US $\$ 1$ per diarrhoea case averted, and 
US $\$ 200$ per death averted. Where formula has already been withdrawn and investment is in education and support (as in Brazil and Honduras), the impact on breast-feeding rates is better and consequently a greater number of diarrhoea cases and deaths are averted, but the costs are higher, ranging from US $\$ 3.58$ per case averted in Brazil to US $\$ 6.74$ in Honduras, and US $\$ 500-800$ per death averted (1992 costs). In India, in a special care unit for LBW babies, considerable savings were made when routine breast-feeding was implemented, as there was no longer a need for 'milk kitchens', and reductions in neonatal infections reduced medication costs. Both diarrhoeal episodes and deaths were reduced (Daga \& Daga, 1985).

Not previously costed before is the impact of $\mathrm{Zn}$ supplementation in averting diarrhoeal cases among LBW infants. Based on our experience of efficacy in north-east Brazil described previously, 8 weeks' supplementation with $5 \mathrm{mg} \mathrm{Zn}$ per child was associated with a $28 \%$ reduction in 0-5-month diarrhoea morbidity. For a population with two to four episodes of diarrhoea in the first 6 months of life, the estimated cost of averting a diarrhoeal episode would be US $\$ 0 \cdot 50-1 \cdot 00$. If effectiveness trials of $\mathrm{Zn}$ supplementation achieve a similar reduction in diarrhoea morbidity, and if the costs are similar under operational conditions, then supplementing LBW infants with $\mathrm{Zn}$ will be one of the most costeffective interventions for reducing diarrhoeal morbidity.

\section{Conclusions}

Since the first series of reviews were written, there have been considerable advancements in some areas, notably in the promotion of breast-feeding. Exclusive breast-feeding is the main focus as this is the feeding mode considered most relevant to child survival. Operational research suggests that implementation of the Ten Steps to Successful Breastfeeding in maternity wards is as yet patchy, and biased towards activities that save staff time and money, rather than counselling-type activities. Some 'babyfriendly' promotions have had limited success in changing exclusive breast-feeding, or the initial impact has been transient. This points to the need for commitment by administrators to provide necessary resources, and routine monitoring of performance indicators. Where programmes include counselling by motivated health staff (as in Santos and Islamabad), and/or by peer counsellors (as in Santiago and Dhaka), substantial effects on the duration of exclusive breast-feeding have been achieved. The previous theoretical calculations of an $8-20 \%$ reduction in $0-5$-month diarrhoeal morbidity (based on medium impact) can be expected to be an underestimate in these situations. The substantial reductions in diarrhoeal morbidity achieved in three high-impact breast-feeding promotion programmes give confidence to the previous estimates that reductions in diarrhoeal morbidity of $20-35 \%$ can be achieved in practice.

For weaning education, there is a continuing need for operational research, and a better understanding of which specific behaviours to target for improved growth. For LBW babies, more randomized controlled trials of $\mathrm{Zn}$ supplementation are needed, and cost-effectiveness studies need to be undertaken. Recent data indicate that LBW can be reduced in the short term by nutritional and nonnutritional interventions. Comparative studies of effectiveness and costs are warranted. For improved food hygiene, there is a need to test the effect on diarrhoea morbidity and mortality of adopting advocated behaviours.

\section{References}

Alvarado RM, Atalah ES, Diaz SF, Rivero SV, Labbé MD \& Escudero YP (1996) Evaluation of a breastfeeding-support programme with health promoters' participation. Food and Nutrition Bulletin 17, 49-53.

Ashworth A \& Draper A (1992) The Potential of Traditional Technologies for Increasing the Energy Density of Weaning Foods. A Critical Review of Existing Knowledge with Particular Reference to Malting and Fermentation. Document WHO/CDD/EDP/92.4. Geneva: WHO.

Ashworth A \& Feachem RG (1985a) Interventions for the control of diarrhoeal diseases among young children: weaning education. Bulletin of the World Health Organization 63, 1115-1127.

Ashworth A \& Feachem RG (1985b) Interventions for the control of diarrhoeal diseases among young children: prevention of low birth weight. Bulletin of the World Health Organization 63, 165-184.

Barros FC, Semer TC, Tonioli Filho S, Tomasi E \& Victora CG (1995) The impact of lactation centres on breastfeeding patterns, morbidity and growth: a birth cohort study. Acta Paediatrica 84, 1221-1226.

Barros FC, Victora CG, Vaughan JP, Teixera AMB \& Ashworth A (1987) Infant mortality in southern Brazil: a population based study of causes of death. Archives of Disease in Childhood 62, $487-490$.

Bentley ME, Dickin KL, Mebrahtu S, Kayode B, Oni GA, Verzosa CC, Brown KH \& Idowu JR (1991) Development of a nutritionally adequate and culturally appropriate weaning food in Kwara State, Nigeria: an interdisciplinary approach. Social Science and Medicine 33, 1103-1111.

Brown KH, Black RE, Lopez de Romana G \& Kanashiro HC (1989) Infant-feeding practices and their relationship with diarrheal and other diseases in Huascar (Lima), Peru. Pediatrics 83, $31-40$.

Brown LV, Zeitlin MF, Peterson KE, Chowdhury AMR, Rogers BL, Weld LH \& Gershoff SN (1992) Evaluation of the impact of weaning food messages on infant feeding practices and child growth in rural Bangladesh. American Journal of Clinical Nutrition 56, 994-1003.

Bukenya GB, Barnes T \& Nwokolo N (1991) Low birthweight and acute childhood diarrhoea: evidence of their association in an urban settlement of Papua New Guinea. Annals of Tropical Paediatrics 11, 357-362.

Ceesay SM, Prentice AM, Cole TJ, Weaver LT, Poskitt EME \& Whitehead RG (1997) Effects on birth weight and perinatal mortality of maternal dietary supplements in rural Gambia: 5 year randomised trial. British Medical Journal 315, 786-790.

Daga SR \& Daga AS (1985) Impact of breast milk on the costeffectiveness of the special care unit for the newborn. Journal of Tropical Pediatrics 31, 121-123.

Feachem RG (1983) Interventions for the control of diarrhoeal diseases among young children: supplementary feeding programmes. Bulletin of the World Health Organization 61, 967979.

Feachem RG (1986) Preventing diarrhoea: what are the policy options? Health Policy and Planning 1, 109-117.

Feachem RG, Hogan RC \& Merson MH (1983) Diarrhoeal disease control: reviews of potential interventions. Bulletin of the World Health Organization 61, 637-640. 
Feachem RG \& Koblinsky MA (1984) Interventions for the control of diarrhoeal diseases among young children: promotion of breast-feeding. Bulletin of the World Health Organization $62,271-291$.

Green CP (1989) Media Promotion of Breastfeeding: A Decade's Experience. Washington, DC: Academy for Educational Development.

Grummer-Strawn LM (1996) The effect of changes in population characteristics on breastfeeding trends in fifteen developing countries. International Journal of Epidemiology 25, 94-102.

Gulmezoglu M, de Onis M \& Villar J (1997) Effectiveness of interventions to prevent or treat impaired fetal growth. Obstetrical and Gynecological Survey 52, 139-149.

Guptill KS, Esrey SA, Oni GA \& Brown KH (1993) Evaluation of a face-to-face weaning food intervention in Kwara State, Nigeria: knowledge, trial, and adoption of a home-prepared weaning food. Social Science and Medicine 36, 665-672.

Haider R, Ashworth A, Kabir I \& Huttly SRA (1998) Peer counsellors improve early postpartum breastfeeding practices in an urban community in Dhaka, Bangladesh. Proceedings of the Nutrition Society 57, 63A.

Haider R, Islam A, Hamadani J, Amin NJ, Kabir I, Malek MA, Mahalanbis D \& Habte D (1996) Breast-feeding counselling in a diarrhoeal disease hospital. Bulletin of the World Health Organization 74, 173-179.

Horton S, Sanghvi T, Phillips M, Fiedler J, Perez-Escamilla R, Lutter C, Rivera A \& Segall-Correa AM (1996) Breastfeeding promotion and priority setting in health. Health Policy and Planning 11, 156-168.

Imong SM, Jackson DA, Rungruengthanakit K, Wongsawasdii L, Amatayakul K, Drewett RF \& Baum JG (1995) Maternal behaviour and socio-economic influences on the bacterial content of infant weaning foods in rural Northern Thailand. Journal of Tropical Pediatrics 41, 234-240.

Kanashiro HC, Fukumoto M, Bentley ME, Jacoby E, Verzosa C \& Brown KH (1991) Use of recipe trials and anthropological techniques for the development of a home-prepared weaning food in the central highlands of Peru. Journal of Nutrition Education 23, 30-35.

Kanashiro HC, Fukumoto M \& Ugaz ME (1994) A Community Intervention to Improve Infant Feeding Practices Related to Diarrhoeal Disease and Growth, and the Evaluation of Changes in Behaviour. Final Report. WHO Programme for Control of Diarrhoeal Diseases. Geneva: WHO.

Lira PIC, Ashworth A \& Morris SS (1996) Low birth weight and morbidity from diarrhea and respiratory infection in northeast Brazil. Journal of Pediatrics 128, 497-504.

Lira PIC, Ashworth A \& Morris SS (1998) Impact of zinc supplementation on immune function, morbidity and growth in term low birth weight infants in northeast Brazil. American Journal of Clinical Nutrition (In the Press).

Lorri W \& Svanberg U (1994) Lower prevalence of diarrhoea in young children fed lactic acid-fermented cereal gruels. Food and Nutrition Bulletin 15, 57-63.

Lutter CK, Perez-Escamilla R, Segall A, Sanghvi T, Teruya K \& Rivera A (1994) The Effect of Hospital-based Breastfeeding Promotion Programs on Exclusive Breastfeeding in Three Latin American Countries. Report for USAID. Mimeo Report International Science and Technology Institute ISTI/LAC HNS. Washington, DC: International Science and Technology Institute.

McDivitt JA, Zimicki S, Hornick R \& Abulaban A (1993) The impact of the Healthcom mass media campaign on timely initiation of breastfeeding in Jordan. Studies in Family Planning 24, 295-309.

Mensah PPA, Tomkins AM, Drasar BS \& Harrison TJ (1988) Effect of fermentation of Ghanaian maize dough on the survival and proliferation of 4 strains of Shigella flexneri. Transactions of the Royal Society of Tropical Medicine and Hygiene 82, 635636.

Mensah PPA, Tomkins AM, Drasar BS \& Harrison TJ (1990) Fermentation of cereals for reduction of bacterial contamination of weaning foods in Ghana. Lancet 336, 140-143.

Monte CMG, Ashworth A, Nations MK, Lima AA, Barreto A \& Huttly SRA (1997) Designing educational messages to improve weaning food hygiene practices of families living in poverty. Social Science and Medicine 44, 1453-1464.

Motarjemi Y, Kaferstein F, Moy G \& Quevedo F (1993) Contaminated weaning food: a major risk factor for diarrhoea and associated malnutrition. Bulletin of the World Health Organization 71, 79-92.

Odugbemi T, Odujinrin OMT, Akitoye CO, Oyerinde JPO \& Esumeh FI (1991) Study on the pH of ogi, Nigerian fermented weaning food, and its effect on enteropathogenic Escherichia coli, Salmonella typhi and Salmonella paratyphi. Joumal of Tropical Medicine and Hygiene 94, 219-223.

Pérez-Escamilla R, Pollitt E, Lōnnerdal B \& Dewey KG (1994) Infant feeding policies in maternity wards and their effect on breast-feeding success: an analytic overview. American Journal of Public Health 84, 89-97.

Prasad B \& Costello AML (1995) Impact and sustainability of a 'baby friendly' health education intervention at a district hospital in Bihar, India. British Medical Journal 310, 621623.

Rea MF \& Berquo ES (1990) Impact of the Brazilian national breast-feeding programme on mothers in Greater Sao Paulo. Bulletin of the World Health Organization 68, 365-371.

Ribeiro HC \& Drasbek CJ (1995) Correct case management of childhood diarrhea: a survey of nine state capitals in northeast Brazil. Bulletin of the Pan American Health Organization 29, 237-249.

Ross DA (1998) Vitamin A and public health: challenges for the next decade. Proceedings of the Nutrition Society 57, $159-165$.

Scrimshaw S \& Hurtado E (1987) Rapid Assessment Procedures for Nutrition and Primary Health Care - Anthropological Approaches to Improving Programme Effectiveness. Los Angeles, CA: UCLA Latin American Center Publications.

Shahidullah M (1994) Breast-feeding and child survival in Matlab, Bangladesh. Journal of Biosocial Science 26, 143-154.

Trussell J, Grummer-Strawn L, Rodriguez G \& VanLangingham $M$ (1992) Trends and differentials in breastfeeding behaviour: evidence from the WFS and DHS. Population Studies 46, 285 307.

United Nations Children's Fund (1996) Evaluation of the BabyFriendly Hospital Initiative and Related Activities in the CEE/ CIS and the Baltics Region, 1993-96. Final Report. New York: UNICEF.

VanDerslice J, Popkin B \& Briscoe J (1994). Drinking-water quality, sanitation, and breast-feeding: their interactive effects on infant health. Bulletin of the World Health Organization 72, 589-601.

Victora CG, Fuchs SC, Kirkwood BR, Lombardi C \& Barros FC (1992) Breast-feeding, nutritional status, and other prognostic factors for dehydration among young children with diarrhoea in Brazil. Bulletin of the World Health Organization 70, 467-475.

Victora CG, Smith PG, Vaughan JP, Nobre LC, Lombardi C, Teixera AMB, Fuchs SM, Moreira LB, Gigante LP \& Barros FC (1988) Influence of birth weight on mortality from infectious diseases: a case-control study. Pediatrics 81, 807811.

Westphal MF, Taddei JAC, Venancio SI \& Bogus CM (1995) Breast-feeding training for health professionals and resultant 
institutional changes. Bulletin of the World Health Organization 73, 461-468.

Wilmoth TA \& Elder JP (1995) An assessment of research on breastfeeding promotion strategies in developing countries. Social Science and Medicine 41, 579-594.

World Health Organization (1981) International Code of Marketing of Breast-milk Substitutes. Geneva: WHO.

World Health Organization (1993a) Breastfeeding Counselling. A Training Course. WHO/CDR/93.3. Geneva: WHO.

World Health Organization (1993b) Improving Complementary Feeding Practices for the Prevention of Diarrhoea. Programme for Control of Diarrhoeal Diseases Report. Geneva: WHO.

World Health Organization (1994) Programme for Control of Diarrhoeal Diseases: Ninth Programme Report 1992-1993. WHO/CDD/94.46. Geneva: WHO.
World Health Organization (1995a) Integrated management of the sick child. Bulletin of the World Health Organization 73, 735740 .

World Health Organization (1995b) Division of Diarrhoeal and Acute Respiratory Disease Control. Interim Report 1994. WHO/CDR/95.1. Geneva: WHO.

World Health Organization (1996) Division of Diarrhoeal and Acute Respiratory Disease Control 1994-1995 Report. WHO/ CHD/96. Geneva: WHO.

World Health Organization/United Nations Children's Fund (1989) Protecting, Promoting and Supporting Breastfeeding: The Special Role of Maternity Services. A Joint WHO/UNICEF Statement. Geneva: WHO.

Wright A, Rice S \& Wells S (1996) Changing hospital practices to increase the duration of breastfeeding. Pediatrics $97,669-675$. 